SCHADE, Burkhard "La declaración de niños menores de edad (preescolares) como testigos en casos de un supuesto abuso sexual"

Polít. crim. Vol. 8, No 16 (Diciembre 2013), Doc. 1, pp. 600 - 611.

[http://www.politicacriminal.cl/Vol_08/n_16/Vol8N16D1.pdf]

\title{
La declaración de niños menores de edad (preescolares) como testigos en casos de un supuesto abuso sexual ${ }^{1}$
}

\author{
Dr. Burkhard Schade \\ Profesor (emérito) Universidad de Dortmund \\ Director Centro de Psicología Forense Bochum
}

El niño como cualquier testigo declara basándose en su memoria, describe un acontecimiento de un pasado más o menos lejano. La pregunta es, por tanto, si la memoria y la declaración son confiables en relación a los acontecimientos fácticos que deben ser esclarecidos. Esto depende de la capacidad del niño como testigo y requiere evaluar y contestar las siguientes preguntas:

- ¿Ha percibido el niño el acontecimiento de forma adecuada? (limitaciones por pánico.)

- ¿Ha retenido el acontecimiento de forma confiable en su memoria? Depende de la relevancia subjetiva del acontecimiento para el niño.

- ¿Puede recordar de manera exacta el acontecimiento o lo ha olvidado completamente o en parte (debido al tiempo pasado)?

- ¿Tiene el niño la capacidad de distinguir entre percepciones o experiencias, por un lado, y fantasía o imaginaciones, por el otro? (depende especialmente de la edad del niño).

- ¿Dispone el niño de un vocabulario o un lenguaje suficiente? (depende de la edad y de la educación del niño).

- ¿Tiene el niño confianza en la persona que le interroga y en la situación del interrogatorio?

- ¿Está la situación obstaculizada por barreras psíquicas (p.e. vergüenza, sentimientos de culpa del niño, etc.)?

- ¿Puede el niño controlar influencias sugestivas? (depende principalmente de la edad del niño).

De la capacidad de ser testigo hay que diferenciar la capacidad para inventar una declaración, es decir, una declaración intencionalmente falsa (mentira). La capacidad de realizar una declaración intencionalmente falsa (narrar un acontecimiento de manera comprensible y más o menos sin contradicciones), depende de dos requisitos, aparte de la edad del niño:

\footnotetext{
${ }^{1}$ El siguiente texto es una transcripción de la conferencia dictada por el autor en el Centro de Estudios de Derecho Penal de la Universidad de Talca el día 20 de marzo de 2013, se reproduce con expresa autorización del autor.
} 
SCHADE, Burkhard "La declaración de niños menores de edad (preescolares) como testigos en casos de un supuesto abuso sexual"

1. Declarar sobre un acontecimiento inventado más o menos complejo es un rendimiento intelectual bastante alto, mucho más alto que relatar sobre algo experimentado o percibido. Esto requiere entonces un nivel intelectual por lo menos promedio. Además se requiere algo de inteligencia un poco creativa que se puede esperar más o menos a partir de los seis hasta los ocho años de edad. Pero también a partir de los cuatro años de edad los niños pueden inventar un acontecimiento a un nivel cualitativamente bajo, que entonces es fácil de detectar.

2. Los conocimientos específicos referidos a la acción del supuesto autor debe haberlos adquirido el niño de otras fuentes, si es que no lo ha experimentado realmente con el inculpado. Este problema se presenta especialmente en caso de declaraciones de niños preescolares. La fuente de los conocimientos específicos declarados por el niño puede ser, por ejemplo:

a. Revistas.

b. Películas pornográficas en el caso de delitos sexuales.

c. Charlas con compañeros/amigos, hermanos u otros familiares.

d. Conocimientos por propia experiencia, los que se pueden adquirir a través de las llamadas "experiencias paralelas", lo que es un caso raro, es decir, el niño ha experimentado en realidad con otra persona los hechos que él atribuye al inculpado.

Cumplir con los dos requisitos significa que el niño dispone de una capacidad definida pero limitada de construir una declaración intencionalmente falsa. La pregunta clave es: ¿Podría el niño haber presentado su declaración sin haber experimentado lo que relata en atención a sus capacidades personales, sus características de la personalidad, su edad, sus motivaciones, sus recuerdos y considerando su situación biográfica actual?

Considerando los aspectos anteriores se presenta el problema esencial: ¿Cómo se pueden evaluar las capacidades de niños preescolares como testigo, especialmente en la edad de alrededor de cuatro años?

La capacidad de relatar un acontecimiento vivido o experimentado en el pasado como requisito de la capacidad para ser testigo se desarrolla en los niños alrededor de los tres a cuatro años de edad. Sin embargo, los niños de esa edad necesitan todavía el apoyo de adultos que hablen con ellos o les interroguen, porque estos niños todavía no disponen de la capacidad de presentar un relato independiente. Los relatos contienen todavía muchos errores o faltas, por lo tanto las declaraciones en muchos casos carecen de validez científica. La exactitud y la validez dependen también de las capacidades narrativas que los niños adquieren en el proceso de aprendizaje del lenguaje.

Para la evaluación de la capacidad como testigo hay que considerar que no es suficiente que un niño pueda recordar un acontecimiento pasado y pueda reproducir el acontecimiento de forma independiente. Hace falta además la capacidad fiable de distinguir entre hechos y fantasía. Los niños a partir de los seis años conocen la diferencia entre acontecimientos 
Polít. crim. Vol. 8, № 16 (Diciembre 2013), Doc. 1, pp. 600 - 611.

[http://www.politicacriminal.cl/Vol_08/n_16/Vol8N16D1.pdf]

reales e imaginados, pero estudios muestran una cierta inseguridad en la distinción. Por ejemplo, si se les presenta una caja diciéndoles que adentro se encuentra un monstruo, a menudo los niños tienen miedo de abrir la caja, suponiendo que no se puede excluir que realmente se encuentra un monstruo adentro. Además hay que considerar que aún cuando puedan distinguir entre realidad y fantasía, a veces nos les importa la distinción. Cualquier cosa puede ser real, siempre y cuando afectan al niño, a sus sentimientos, actitudes y a su conducta.

Otro problema es la sugestibilidad elevada de niños menores. La sugestibilidad se entiende como la disposición para integrar informaciones posteriores en su sistema de pensar, recordar y más adelante relatar estas informaciones como hechos vividos.

Ejemplos de estudios experimentales:

1. Niños entre tres y seis años jugaron con un hombre, después se les interrogaba, sugiriéndoles que algo desagradable había pasado con este hombre, que éste se había comportado fresco y descarado. Cinco de quince niños relataron después que el hombre les dio besos, otros relataron que estaban con el hombre en el baño y se bañaron con él. Todos estos niños estaban convencidos que experimentaron estas situaciones.

2. Niñas de cuatro años de edad estaban en compañía de un niñero varón. Once días después se pusieron en contacto con ellas y se les dio la información de un mal comportamiento del hombre que no era verdad. Una niña relató después que el hombre tenía un fusil y quería matarla. Otra niña relató que en el cuarto también se encontraba un perro. Y otra niña relató que el perro la había mordido.

Lo que se ve de estos estudios es que no todos los niños caen en la trampa de influencias sugestivas. Por lo tanto resulta necesario averiguarlo caso por caso. Se habla de sugestibilidad de la declaración, es decir, ceder influencias sugestivas en un interrogatorio o una conversación. En fin, no se puede confiar en que todos los niños de alrededor de cuatro años tengan capacidad suficiente para ser testigo.

En resumen, la capacidad para ser testigo de un niño de alrededor cuatro años o menos es dudosa y requiere un examen a fondo en cada uno de los casos.

¿Cuáles son las condiciones psicológicas de influencias sugestivas y de la sugestibilidad de los niños? En cuanto a las influencias sugestivas, no es lo más frecuente o típico que un adulto influya al niño intencionalmente para obtener una declaración falsa. Más probable es que los adultos ejercen las influencias sugestivas sin conocer los riesgos de falsificar y distorsionar los recuerdos de los niños en sus declaraciones posteriores.

¿A qué se deben las influencias sugestivas de adultos que interrogan al niño?

En primer lugar una entrevista sugestiva contiene las así llamadas preguntas sugestivas. Se trata de preguntas “cerradas”que sólo permiten respuestas de sí o no. Por ejemplo: ¿el 
SCHADE, Burkhard "La declaración de niños menores de edad (preescolares) como testigos en casos de un supuesto abuso sexual"

hombre te tocaba al pene o el poto? Además, con esta pregunta se pasa al niño la información que hay adultos que lo hacen. Aún mayor influencia sugestiva tiene la pregunta: “¿te tocaba el pene con la mano derecha o mano izquierda?”, antes de que el niño hubiese dicho que el adulto le hubiera tocado!

Ejemplo de un estudio experimental: Se preguntó lo siguiente a niños preescolares en dos grupos después de una consulta médica:

A un grupo se le preguntó antes de que los niños hubiesen relatado que el médico les había besado (que no era verdad), cuántas veces el médico les había besado. A otro grupo se le preguntó si el médico les había besado.

Resulta del experimento que el porcentaje de respuestas afirmativas (besos) era mucho más alto en el grupo de interrogatorio sugestivo que en el otro. En segundo lugar, una influencia sugestiva tiene lugar, si el adulto interroga al niño estando convencido de la veracidad del supuesto hecho y adquiere una alta motivación para buscar la confirmación de su sospecha. Esto se muestra a veces por una presión psicológica sobre el niño para obtener de él la respuesta afirmativa. Esto sucede, por ejemplo, con estas técnicas de interrogación:

- Si tú dices lo que el tío hizo contigo te regalo un juguete.

- Tus compañeros ya relataron lo que pasó - ahora te toca a ti.

- Tus compañeros relataron que el tío les tocaba al pene,

- Respuestas afirmativas están reforzadas por elogio (niño muy valiente, darle cariño, varón bravo, estoy orgulloso de ti...), lo que lleva al niño a contestar de la misma manera. Así el niño aprende lo que el adulto espera de él.

- Si se transmite al niño una imagen negativa del inculpado, por ejemplo, que él se encuentra en la cárcel, es más probable que el niño declare que el hombre se comportó mal.

Se presentó hace poco en Alemania este ejemplo en un interrogatorio policial con un varón de cuatro años:

- ¿Pasaste la noche ahí (con el inculpado) muchas veces?

$-¿ \mathrm{Si}$ ?

- ¿Cuántas veces? ¿Lo sabes?

- 100 años.

$-i 100$ veces?

$-\mathrm{Si}$.

- ¿Entonces muchas veces?

$-\mathrm{Si}$.

Se negociaba la verdad con el niño que no era la verdad de él. La madre relató que el niño definitivamente pasó la noche una sola vez. Más adelante en el mismo interrogatorio: 
Polít. crim. Vol. 8, No 16 (Diciembre 2013), Doc. 1, pp. 600 - 611.

[http://www.politicacriminal.cl/Vol_08/n_16/Vol8N16D1.pdf]

- ¿Tú sabes que policías son superhéroes? Tú también para nosotros eres un superhéroe, si tú nos ayudas y nos relatas que ha hecho el tío contigo, para que no lo pueda hacer con otros niños más.

Esto es completamente inaceptable en un interrogatorio profesional.

Ejemplo de otro estudio experimental: Se pidió a una trabajadora social interrogar a niños preescolares en relación con un acontecimiento en dos grupos. Para el interrogatorio del grupo A ella tenía informaciones verídicas sobre el acontecimiento; para el grupo B la trabajadora social recibió informaciones falsas sobre el acontecimiento sin saberlo. En el grupo $B$, el treinta y cuatro por ciento de los niños (entre tres y cuatro años) y el dieciocho por ciento de los niños (entre cinco y seis años) relataron sobre la base de la información falsa. Se ve de este estudio que la convicción del adulto sobre la veracidad del supuesto acontecimiento tiene una alta influencia en las declaraciones de niños.

Un papel importante tiene la autoridad del adulto, que refleja la credibilidad del adulto para el niño. Los padres, el agente de policía, el juez u otras autoridades siempre tienen razón para el niño. Si el niño cree que estas autoridades tienen la sospecha que algo ha ocurrido, para el niño eso es ya un hecho. Esto se puede ver por un estudio experimental referido a preguntas "sin sentido": Se preguntó a niños entre cinco y siete años de edad si la leche es más grande que el agua. Resultado: la mayoría de estos niños respondió con un sí o un no.

Los interrogatorios múltiples producen en el niño la impresión que todavía no ha declarado lo suficiente o ha declarado algo falso. Esto le motiva a ampliar su declaración en forma cualitativa y cuantitativa. Por ejemplo: relatar más hechos, nuevos hechos, una frecuencia superior de situaciones, o declaraciones que carecen completamente o parcialmente de credibilidad.

En resumen, las influencias sugestivas producen casi obligatoriamente distorsiones y falsificaciones de la declaración de los niños preescolares y aún más si coinciden con una sugestibilidad elevada del niño.

Ahora pasamos al problema de sugestibilidad elevada de niños menores, es decir, la capacidad limitada de controlar influencias sugestivas, por la cual se aumenta la probabilidad de distorsiones y falsificaciones del recuerdo y, en consecuencia, de la declaración. Se define sugestibilidad como la disposición de introducir informaciones posteriores en el sistema cognitivo de percepción del recuerdo como hechos percibidos y experimentados. La sugestibilidad como rasgo de la personalidad casi no existe, a veces por alta timidez.

Lo que cuenta es, por tanto, lo siguiente: la situación psicosocial actual del niño que, por las circunstancias especiales, en un contexto de sospecha tiene probablemente más necesidades de atención cariñosa de parte del adulto. Por ello, quiere comportarse bien y cumplir con las expectativas del adulto, por ejemplo, si se llevaron al niño a un hogar. Además, hay que considerar que el niño ya ha olvidado completamente o en parte el acontecimiento y llena 
SCHADE, Burkhard "La declaración de niños menores de edad (preescolares) como testigos en casos de un supuesto abuso sexual"

las lagunas del recuerdo con fantasía. Además a un niño con recuerdos deficientes le es muy difícil atribuir sus conocimientos al origen de procedencia. Esto aumenta la probabilidad de relatar algo como vivido que, en realidad, se debe a la información del adulto. Se habla en estos casos de una inseguridad en el control del origen o de la fuente del relato o de detalles del relato.

Niños en la edad preescolar atribuyen al adulto algo como una omnipotencia. El adulto, especialmente los padres, representan para ellos la persona más competente, que sabe todo, en quien el niño tiene toda la confianza, dando por hecho que jamás le engañará. En el caso de preguntas repetidas ciertos niños desarrollan una tendencia de decir "sí". El famoso psicólogo Piaget habla de convencimientos sugeridos y describe esta actitud del niño como "me da lo mismo". Se puede describir el origen y la historia de la declaración de un niño como un proceso psicológico de aprendizaje.

En primer lugar: se trata de un proceso cognitivo de aprendizaje: en el transcurso de la historia de la declaración, el niño aprende, por ejemplo, lo que es sexualidad o abuso sexual, las acciones correspondientes y aprende además cuáles son las opiniones y las actitudes de los adultos al respecto que quieren saber de él.

En segundo lugar: existe un proceso emocional de aprendizaje. El niño adopta el rol social como víctima de un abuso sexual y poco a poco crecen en él sentimientos de odio o venganza contra la persona acusada o sentimientos de desesperación o tristeza.

En tercer lugar: se presenta también un proceso motivacional del aprendizaje. En el niño crece una disposición motivacional de adaptar los contenidos de su declaración a las expectativas supuestas de los adultos. Estos procesos de aprendizaje forman la base para alteraciones, es decir, ampliaciones cualitativas y cuantitativas en el transcurso de los interrogatorios. Por eso para evaluar la verdad de una declaración tiene alta significación la primera declaración siempre y cuando no está afectada por influencias sugestivas lo que se evalúa con las preguntas siguientes:

- ¿Cuándo el niño declaró por primera vez?

- ¿A quién declaró y en qué situación?

- ¿Declaró espontáneamente, es decir sin preguntas previas?

- ¿Declaró en terapia?

- ¿Declaró contestando a preguntas sugestivas sobre la base de una sospecha?

- ¿Cuáles eran las respuestas y reacciones después de la primera declaración en el entorno social?

Después se debe verificar si más adelante se interrogó al niño nuevamente y cuantas veces y en qué forma (p.e. presentar dudas, afirmaciones, reforzamientos, etc.). En caso que se puedan identificar influencias sugestivas desde la primera declaración y en los interrogatorios posteriores que llevaron al niño a una ampliación cualitativa y/o cuantitativa de la declaración, la declaración está "contaminada" o "infectada" porque ya no se puede excluir o quizás es muy probable que influencias sugestivas produjeran distorsiones y 
Polít. crim. Vol. 8, No 16 (Diciembre 2013), Doc. 1, pp. 600 - 611.

[http://www.politicacriminal.cl/Vol_08/n_16/Vol8N16D1.pdf]

falsificaciones de los recuerdos del niño. Entonces la declaración no puede ser un medio de prueba. Para ilustrar toda la problemática de distorsiones y falsificaciones de los recuerdos y de las declaraciones de niños se puede acudir a un caso auténtico de un varón de ocho años:

- Primera declaración: No pasó nada, los demás niños se lo inventaron y mienten.

- Segunda declaración: yo no puedo recordar nada, no sé nada.

- Tercera declaración: si ha pasado algo (abuso sexual) por lo menos yo no estaba presente.

- Cuarta declaración (después de haber recibido la información que se había filmado un video): preséntame el video para volver a recordar.

- Quinta declaración (después de haber recibido la información que no se pudo encontrar el video), el varón muestra señales verbales y no verbales de susto, tristeza e irritación.

- Sexta declaración: ahora voy a decir al juzgado todo lo que ellos (autores del delito) han hecho conmigo.

- Séptima declaración: ¿Hay alguien que me va a proteger de ellos en la sala de audiencia?

A veces el proceso psicológico en el transcurso del tiempo lleva al niño a declaraciones espectaculares y fantásticas que carecen completamente de credibilidad. Ejemplo auténtico de una niña de seis años con un desarrollo y personalidad normal: ella relató que las tías le habían puesto un dedo sucio con heces humanas en su vagina, en su ano y en su boca. Una tía le había dicho que le pegaría a los niños que denunciaran algo, les mataría y les transformaría en una muñeca barbie.

El método válido con una base científica para distinguir una declaración inventada de una declaración verídica es el análisis de contenido de la declaración según los siguientes criterios de credibilidad:

1. Consistencia lógica: No hay contradicciones lógicas en la declaración, como por ejemplo: El niño relata un hecho que sucedió en la casa, pero resulta que en ese día el inculpado no estaba en la casa. El niño que hace una declaración falsa no puede evitar contradicciones, especialmente porque no puede anticipar preguntas con que se quiere controlar la veracidad de la declaración.

2. Presentación no estructurada: Un niño que declara sobre un hecho que realmente aconteció puede saltar entre los contenidos del relato, p.ej. cuenta primero los efectos de una acción del inculpado, después cómo había comenzado todo, después cómo conoció al inculpado, etc. En cambio, un niño que declara sobre un hecho inventado debe estructurar muy bien su relato para no perder el contexto.

3. Cantidad de detalles: Normalmente la declaración sobre un acontecimiento experimentado contiene muchos más detalles que una declaración inventada. Normalmente la declaración inventada se reduce a los detalles esenciales de la acción supuesta del autor. 
SCHADE, Burkhard "La declaración de niños menores de edad (preescolares) como testigos en casos de un supuesto abuso sexual"

4. Combinación de lugar y tiempo: La declaración verídica contiene informaciones sobre lugares y tiempos que reflejan el espacio de vida común entre el inculpado y la supuesta víctima, lo que permite rechazar la hipótesis que el niño podría haber relatado algo que, en realidad, ha experimentado con otra persona. Indicaciones:

- Estadía común en la casa de uno de los dos.

- Una excursión con el autor.

- Haber pasado vacaciones en común, etc.

5. Descripción de interacciones: La declaración verídica sobre un acontecimiento más o menos complejo contiene siempre la descripción de múltiples interacciones entre el testigo y el supuesto autor, p.ej. acción-reacción, acción nueva y reacción nueva, etc. El escenario de una acción cuesta inventarlo. Entonces se reduce una declaración falsa a veces a una sola frase: "después me pegó".

6. Reproducción de conversaciones: La declaración verídica tiene, en muchos casos, recuerdos del diálogo entre el niño y el supuesto autor como instrucciones, elogios, críticas, motivos, actitudes, etc. Es raro que los dos no conversen y es difícil inventar una conversación que indica una cierta autenticidad.

7. Descripción de complicaciones en el transcurso del hecho: en muchos casos se presentan complicaciones como: alguien llama por teléfono, se oye el timbre de la puerta, o: se cae un vaso, está llegando otra persona, etc. Justamente en el contexto de este criterio de realidad no se discute si un niño quizás podría inventar una complicación, sino que es muy poco probable que se le ocurra la idea de inventarlo. Por eso tiene alta fuerza probatoria. Ejemplo auténtico: durante la acción de un abuso sexual de un niño, se sintió un olor muy fuerte porque en la cocina se quemó la comida.

8. Descripción de detalles especiales: Detalles especiales son aquellos que no se esperan en declaraciones inventadas sobre la base de un esquema, es decir, con base en una idea de cómo el hecho podría haber ocurrido, son detalles originales, no típicos. Por ejemplo: de repente en un caso de supuesto abuso sexual, el autor sufre de una disfunción eréctil o el niño está viendo la tele durante la acción. Otro ejemplo auténtico: una niña de cuatro años relata un hecho de un abuso sexual pero riéndose, porque había chupado el pene del autor como un lollipop. Es imposible que una niña de esta edad pueda inventar este detalle.

9. Descripción de detalles de poca importancia: Son detalles en la declaración que no tienen nada que ver con el hecho, p.ej. el niño relata que en tal día estaba lloviendo/había mucho sol.

10. Descripción de elementos no entendidos: Este criterio de realidad se presenta muchas veces en relatos de niños que describen un abuso sexual sin entender la anatomía y los procesos fisiológicos del supuesto autor. Como les falta el conocimiento de que por la 
Polít. crim. Vol. 8, No 16 (Diciembre 2013), Doc. 1, pp. 600 - 611.

[http://www.politicacriminal.cl/Vol_08/n_16/Vol8N16D1.pdf]

tocación al pene del autor puede haber una excitación sexual, entonces no puede inventar una declaración correspondiente.

11. Descripción con referencia indirecta al hecho: Ejemplo: un niño relata que el aspecto del pene del autor era muy diferente del de su papá.

12. Descripción de procesos psíquicos propios: No es suficiente que el niño declare que sentía tristeza o rabia, etc., pues estos sentimientos podrían fácilmente ser inventados. El criterio de realidad se cumple si el niño relata sobre los cambios en sus sentimientos, p.ej. de irritación hacia la rabia o tristeza, aumento o disminución de miedo.

13. Descripción de procesos psíquicos del autor del hecho: El niño describe, p.ej. la excitación sexual del autor, la satisfacción sexual, o relata simplemente alegría, desilusión o rabia.

14. Elementos específicos del delito en la declaración: El niño/la niña relata que el autor aplicaba saliva o crema hidratante para facilitar la penetración.

Los siguientes cinco criterios de credibilidad se refieren a declaraciones típicas de niños que mienten. Tienen alta fuerza probatoria porque indican la motivación de ellos de presentarse como testigos creíbles.

15. Correcciones espontáneas de la declaración: Un niño que declara sobre un acontecimiento inventado tiene alta motivación de evitar correcciones en su declaración para no admitir dudas sobre la credibilidad de su declaración.

16. Admisión de errores de la memoria: Un niño que hace una declaración inventada trata de persuadir que está completamente seguro de sus recuerdos.

17. Objeciones respecto a la validez de la declaración: Un niño que relata sobre algo que realmente ha experimentado, podría admitir que no está seguro respecto a la fuente de su declaración p.ej. si un detalle realmente lo ha experimentado o vivido, o si lo sabe de otra persona.

18. Auto-inculpaciones: Un niño que hace una declaración verídica puede admitir que se siente parcialmente culpable de lo que ha ocurrido porque dice que se ha comportado mal con el autor.

19. Descargar al inculpado: En una declaración verídica se presentan observaciones como que el inculpado no ha utilizado violencia o ha hecho amenazas; o que, más allá de los hechos, era una persona agradable y simpática, y quiere estar otra vez junto con él en el futuro.

Nota: El método de análisis de contenido es un método cualitativo y no cuantitativo, es decir, de ninguna manera se debe esperar que todos o la mayoría de los criterios de realidad se deban cumplir en la declaración del niño. Un alto grado en la presentación de los 
SCHADE, Burkhard "La declaración de niños menores de edad (preescolares) como testigos en casos de un supuesto abuso sexual"

criterios de realidad indica sin embargo siempre una alta probabilidad de que la declaración tiene como base un acontecimiento real. Un grado muy disminuido en la presentación de estos criterios - normalmente en los relatos de niños menores - no indica que se trata de una declaración falsa, sino solamente que con el método del análisis del contenido no se puede verificar la hipótesis de la vivencia.

Un método adicional para evaluar la credibilidad de la declaración de un testigo es la prueba de constancia. Esta prueba se basa en la hipótesis de que un testigo que declara desde su memoria puede declarar en cada interrogatorio, o después de largos períodos de tiempo, lo mismo del contenido principal del interrogatorio anterior. En cambio, un testigo que relata una mentira debe tratar de recordar en cada interrogatorio qué ha declarado en determinada pregunta de un interrogatorio anterior. Esto produce necesariamente contradicciones, es decir, inconstancias que son un indicador seguro de que la veracidad de la declaración es dudosa. Pero a base de la psicología de la memoria no se puede esperar la constancia en cuanto a todos los detalles. Hay que diferenciar entre constancias esperadas e inconstancias esperadas:

\section{Constancias esperadas}

- Descripción de lo esencial de la supuesta acción.

- Descripción del propio rol o actividad en el acto.

- Identificación de las personas que participaron en el acto.

- Identificación del lugar.

- Identificación de objetos relevantes en el transcurso de la acción.

- Descripción de luz u obscuridad.

- Descripción de las posiciones de los cuerpos en el caso de acciones corporales.

Inconstancias esperadas.

- Descripción de las acciones periféricas.

- La atribución correcta de las acciones periféricas a la acción central, ¿qué pasó antes y después?

- El orden de varias situaciones o acciones.

- Informaciones sobre estimaciones/evaluaciones (p.e. frecuencias, fechas).

- Informaciones sobre los cambios de posición del cuerpo y el orden.

- Informaciones textuales de charlas o conversaciones.

- Informaciones sobre sensaciones desagradables en el cuerpo (p.ej. dolores) en cada una de las fases de la acción.

Los resultados del análisis del contenido y los resultados de la prueba de constancia permiten decidir si la calidad de una declaración del testigo está encima de sus capacidades para construir una declaración falsa. Si esto es así, la prueba indica que la declaración se refiere a un acontecimiento real. Si está por debajo de esas capacidades, entonces indica que la declaración podría ser completamente o en parte falsa, es decir: inventada. 
Polít. crim. Vol. 8, No 16 (Diciembre 2013), Doc. 1, pp. 600 - 611.

[http://www.politicacriminal.cl/Vol_08/n_16/Vol8N16D1.pdf]

Partiendo del análisis de la calidad de la declaración, pasamos a la comprobación de la validez de la declaración falsa según las dos hipótesis alternativas, es decir otra vez la hipótesis de la declaración intencionalmente falsa y la hipótesis de la declaración falsa por error.

La hipótesis de la declaración intencionalmente falsa se comprueba por un análisis de la motivación y sus modificaciones en el período entre el acontecimiento y la declaración, a veces muchos años después. Para comprobar si se trata de una declaración intencionalmente falsa se pregunta la pregunta: ¿Tuvo el niño algún motivo de inculpar al supuesto autor como, por ejemplo, hacerle daño o salir de una situación familiar desagradable? Por lo tanto, lo que se debe esclarecer son las actitudes y sentimientos del niño respecto del inculpado en el contexto de su situación personal y las modificaciones respectivas en el curso del tiempo. Un ejemplo para evadir de una situación desagradable: un niño hace la declaración falsa que se siente maltratado en la casa. Un ejemplo para hacer daño a otra persona: el niño quiere que su mamá deje a su compañero.

La capacidad de construir una declaración falsa casi nunca depende de la personalidad del testigo o de sus actitudes hacia la verdad y la mentira, si miente o dice la verdad. Esto depende casi exclusivamente de si el niño como tal tiene, en la situación concreta, un motivo cierto y psicológicamente comprensible para decir la verdad o para mentir. Niños mayores están a veces obligados de mentir para reservar su espacio de vida que está restringido por las normas socioculturales de sus padres. De ninguna manera se puede deducir de esto que las declaraciones de estos testigos normalmente son mentiras. La hipótesis de una declaración falsa por error se comprueba por medio de un análisis exacto del origen y de la historia de la declaración. Causas de las cuales surgen declaraciones erróneas:

- Recuerdo limitado o deficiente, cubrir lagunas en el recuerdo por suposiciones.

- Influencias sugestivas sobre el recuerdo o la declaración del testigo.

- Influencias autosugestivas sobre el recuerdo y la declaración del testigo, que se presentan cuando el niño tiene una motivación de falsificar el recuerdo de un hecho vivido.

Nota muy importante: Hay limitaciones en la aplicación del método del análisis de contenido y de la prueba de constancia porque ambos métodos sirven especialmente para comprobar la hipótesis de la declaración intencionalmente falsa, pero para la declaración falsa por error tiene una validez muy reducida y poco válida. Ello porque una declaración sugerida y entonces falsa por error puede cumplir perfectamente con los criterios de credibilidad y puede tener alta constancia porque está retenida en la memoria como una declaración verídica.

Se puede y debe aplicar el método del contenido y la prueba de constancia si la declaración del niño presenta estos requisitos:

- Si no hay indicaciones concretas de influencias sugestivas pero hay indicaciones por las cuales se debe comprobar la hipótesis de una mentira. 
SCHADE, Burkhard "La declaración de niños menores de edad (preescolares) como testigos en casos de un supuesto abuso sexual"

- Si el niño dispone de las capacidades como testigo, lo que es más probable a partir de seis años de edad, es decir cuando el niño es un niño escolar.

- Si existe una declaración más o menos elaborada y concreta y detallada, también más probable a partir de los seis años de edad.

- Si la declaración está documentada en forma objetiva (sea por audio o video).

- Si el niño hizo la declaración a corto plazo después del acontecimiento.

La conclusión de estos requisitos por un lado y considerando los resultados en cuanto a los criterios de capacidad para ser testigo, y considerando el problema de las influencias sugestivas y de la sugestibilidad elevada en niños menores por otro lado se puede resumir:

La probabilidad que la declaración de un niño preescolar es inventada es mínima y se la detecta fácilmente por su mala calidad (pocos detalles, pocos detalles concretos, contradicciones y contenidos muy poco realista etc.).

A partir de los seis años de edad, o mejor dicho, si se trata de niños escolares, esto puede ser muy diferente. Entonces vale: un niño de alrededor de cuatro años -preescolarnormalmente no miente cuando relata un abuso sexual si no está convencido de la veracidad de su relato. Pero esto no significa que su relato se refiere a un acontecimiento real. Por posibles (múltiples) influencias sugestivas al recuerdo y a la declaración y por la sugestibilidad elevada, a veces es muy difícil excluir con validez científica que se trata de una declaración completamente o en parte falsa por error.

Aparte de los métodos científicos de evaluación presentados, se aplican todavía métodos que no tienen validez científica, entre ellos:

1. La impresión subjetiva personal.

2. Dibujos de niños. La interpretación por los adultos es muy subjetiva y a veces permite más bien un vistazo a la personalidad del adulto que a la personalidad del niño.

3. Técnicas de proyección (tests) que carecen de objetividad, por lo que no tienen validez científica, indican más bien rasgos del adulto.

4. Trastornos o problemas de la personalidad del niño:

a. empeoramiento en el rendimiento escolar;

b. demasiada intimidad o evitación de intimidad con personas en el contorno social;

c. fuga del hogar;

d. enuresis o encopresis;

e. masturbación u otra forma de una conducta sexual;

f. sentimientos de culpa;

g. agresividad.

No existen índices específicos de un abuso sexual, sin embargo, niños que realmente han sufrido de un abuso sexual pueden mostrar estos índices. Pero niños con otros problemas de conducta o de personalidad también presentan éstas señales. Por lo tanto no se puede deducir de ellas un abuso sexual. Esto carece completamente de validez científica. 